\title{
THE RATE OF UPTAKE OF CHLORIDE, PHOSPHATE AND SULPHATE IN PERENNIAL RYEGRASS ${ }^{1}$ )
}

\author{
W. DIJKSHOORN \\ Institute for Biological and Chemical Research on Field Crops \\ and Herbage, Wageningen, Holland
}

\section{SUMMARY}

From experiments on anion antagonism, on the effect of equivalent substitution of anions in nutrient solutions and on the distribution of the anionic elements over the lower and higher parts of herbage it has been inferred that the rate of uptake decreases according to the sequence: chloride, phosphate, sulphate.

\section{INTRODUCTION}

In studying the effect of fertiliser salts on the mineral composition of perennial ryegrass it was found that chloride can be absorbed in large amounts. The large increase of $\mathrm{Cl}$ in the herbage following the application of chloride was observed to be associated with an increase in total anions $(\mathrm{Cl}+\mathrm{P}+\mathrm{S}$ $+\mathrm{N}$ ) upto a limiting value, as indicated by the occurrence of anion antagonism.

This antagonism was reflected in a distinct decline in $\mathrm{S}$, whereas $\mathrm{P}$ was practically unaffected (DijkshoorN, 1957, 1958 a).

If it is assumed that in the case of antagonism there is first of all a reduction in the uptake of the element most difficultly absorbed by the herbage, this would indicate that sulphate is less readily absorbed than phosphate.

The results of fertilisation experiments (Dijkshoors, 1957) failed to show any marked difference in the effects of application of either phosphate or sulphate on the mineral composition of the herbage in terms of total cations and total anions equivalents. However, in many cases fertilisation experiments with soilgrown plants cannot be applied to the comparison of the rate of uptake of different elements. Owing to limited solubility, preferential adsorption by the soil system and other causes, mutually equivalent additions may not go together with mutually equivalent increases in the amount available. For this reason the results should not be relied upon for the purpose of general information on the relative rate of uptake of different elements.

As a result of these interfering effects it is necessary to evaluate the relative rate of uptake in the absence of soil. This may be carried out quite simply by the use of nutrient solutions.

In the present communication the anion antagonism resulting from chloride fertilisation is first demonstrated. Thereafter, results are discussed on the effect of application of series of solutions of equal ionic strength, in which one of the anions has been gradually substituted by another anion, on the anionic make-up of the herbage. From these it has been inferred that the order of decreasing rate of uptake in the herbage agrees with the order inferred from anion antagonism, viz. chloride, phosphate, sulphate. Further evidence on the

1) Received for publication July 26, 1958. 
correctness of this sequence was obtained from a study of data of Kemp and Dijkshoors (1956) on the distribution of the elements over the top and bottom parts of grass herbage.

\section{EXPERIMENTAL}

The pot culture experiment has been made in the manner previously described, by planting the treated pots with perennial ryegrass, clipping the grass after three days and collecting the harvest produced by regrowth four weeks thereafter. The treatments include a basic dressing with $20 \mathrm{ml} 1 \mathrm{~N}$ potassium nitrate $(280 \mathrm{mg} \mathrm{N}$ ). One series of pots was given increasing amounts of $1 \mathrm{~N}$ magnesium chloride (chloride series), another series received corresponding amounts of magnesium sulphate (sulphate series). A sandy soil was used, the pots having a capacity of $5 \mathrm{~kg}$. Three replicates of each treatment were prepared in order to get sufficiently large samples for analysis.

In the solution culture experiments use was made of glass containers of six liters capacity and provided with perforated covers (50 perforations of $1 \mathrm{~cm}$ diameter). The roots of the plants, previously grown in the experimental garden, were cleaned from soil by rinsing of the roots with running tap water. Thereafter, the plants were made up into bundles of suitable size which were fixed in the holes of the covers with cotton-wool. After repeated thorough rinsing of the roots the plants were clipped and placed on the experimental solutions. During the subsequent regrowth the solutions were daily made up to 6 liters with demineralised water. After four weeks the herbage produced on the solutions was harvested.

\section{Results}

The data referring to the pot culture experiment on the effect of chloride and sulphate dressings are listed in table 1 . In Fig. 1 total cations $\mathrm{C}(=\mathrm{K}+$ $\mathrm{Na}+\mathrm{Mg}+\mathrm{Ca})$, the non-nitrogenous anions $\mathrm{A}(=\mathrm{Cl}+\mathrm{P}+\mathrm{S})$, nitrogen $\mathrm{N}$ and total anions $\mathrm{A}+\mathrm{N}$ in the herbage, expressed as $\mathrm{mg}$ equivalents per $\mathrm{kg}$ dry weight, are plotted on a logarithmic scale against the number of $\mathrm{mg}$ equivalents chloride $(\mathrm{Cl})$ or sulphate $(\mathrm{S})$ applied.

Total cations and total anions have been indioated by lines running parallel, on the assumption that the cation-anion ratio $\mathrm{C} /(\mathrm{A}+\mathrm{N})$ has not been affected by the treatments. The lines have been drawn on the same linear distance in the two series, indicating there is no evidence of any effect of the substitution of chloride by sulphate in the dressing on the value of the cation-anion ratio. It is seen that the experimental data agree with these assumption except for the low value of total cations in the $40 \mathrm{mg}$ equivalents $\mathrm{Cl}$ treatment which is associated with an unexpected low value for $\mathrm{K}$ (table 1).

Phosphorus has been included in the anions A as trivalent. Based on monovalent phosphorus values are obtained for the cation-anion ratio of about 0.54 . Nitrogen approaches very closely the value of $2600 \mathrm{mg}$ equivalents which was previously found to occur at the same age of four weeks without a shortage of nitrogen (Dijkshoorn, $1958 \mathrm{~b}$ ). The cation-anion ratio, based on monovalent phosphorus, was 0.56 .

This correspondence of the internal mineral balance in both experiments is related to the fact that they were both conducted in summer. In the early 
Table 1 Yield in $g$ per pot and mineral composition of the herbage produced in the experiment on the effect of chloride (Cl) and sulphate $\left(\mathrm{SO}_{4}\right)$ dressings in amounts from nil to $40 \mathrm{mg}$ equivalents per pot. Phosphorus trivalent, nitrogen monovalent.

\begin{tabular}{|c|c|c|c|c|c|c|c|c|c|c|}
\hline \multirow{2}{*}{\multicolumn{2}{|c|}{$\begin{array}{l}\text { treatment } \\
\text { mg eq }\end{array}$}} & \multirow{2}{*}{ yield } & \multicolumn{8}{|c|}{ mg equivalents per $\mathrm{kg}$ dry matter } \\
\hline & & & $\mathrm{K}$ & $\mathrm{Na}$ & $\mathrm{Mg}$ & $\mathrm{Ca}$ & $\mathrm{Cl}$ & $\mathbf{P}$ & S & $\mathbf{N}$ \\
\hline $\mathrm{Cl}$ & $\begin{array}{r}0 \\
10 \\
20 \\
30 \\
40\end{array}$ & $\begin{array}{l}13.8 \\
12.9 \\
12.7 \\
13.3 \\
15.1\end{array}$ & $\begin{array}{l}1248 \\
1300 \\
1330 \\
1410 \\
1240\end{array}$ & $\begin{array}{l}84 \\
84 \\
74 \\
77 \\
71\end{array}$ & $\begin{array}{l}159 \\
208 \\
218 \\
228 \\
228\end{array}$ & $\begin{array}{l}281 \\
381 \\
346 \\
349 \\
360\end{array}$ & $\begin{array}{r}231 \\
714 \\
775 \\
950 \\
1045\end{array}$ & $\begin{array}{l}347 \\
326 \\
338 \\
334 \\
326\end{array}$ & $\begin{array}{l}335 \\
254 \\
204 \\
198 \\
183\end{array}$ & $\begin{array}{l}2585 \\
2650 \\
2700 \\
2570 \\
2535\end{array}$ \\
\hline $\mathrm{SO}_{4}$ & $\begin{array}{r}0 \\
10 \\
20 \\
30 \\
40\end{array}$ & $\begin{array}{l}14.6 \\
13.2 \\
11.8 \\
15.0 \\
13.7\end{array}$ & $\begin{array}{l}1265 \\
1150 \\
1228 \\
1160 \\
1222\end{array}$ & $\begin{array}{l}77 \\
77 \\
77 \\
55 \\
71\end{array}$ & $\begin{array}{l}169 \\
179 \\
184 \\
218 \\
228\end{array}$ & $\begin{array}{l}317 \\
296 \\
317 \\
281 \\
281\end{array}$ & $\begin{array}{l}228 \\
268 \\
206 \\
209 \\
231\end{array}$ & $\begin{array}{l}360 \\
326 \\
330 \\
347 \\
364\end{array}$ & $\begin{array}{l}348 \\
331 \\
385 \\
413 \\
413\end{array}$ & $\begin{array}{l}2320 \\
2500 \\
2760 \\
2265 \\
2565\end{array}$ \\
\hline
\end{tabular}

spring and in autumn ageing takes place at a slower rate and higher $\mathrm{N}$ values are found after four weeks regrowth at a sufficiently high nitrogen level.

As Fig. 1 shows, the chloride dressings have been associated with a marked increase in the non-nitrogenous anions $\mathbf{A}$. This rise is also present in total anions $\mathrm{A}+\mathrm{N}$ and a level is reached of $4000 \mathrm{mg}$ equivalents total anions. According to previous results (Dijkshoons, 1958 a) this represents the saturation level and its appearance is associated with anion antagonism.

The increase in the non-nitrogenous anions $\mathrm{A}$ as a result of sulphate dressing is negligible, as shown by the graph referring to the sulphate series. Here total anions $\mathrm{A}+\mathrm{N}$ remains below the saturation level in the herbage and consequently anion antagonism cannot be expected.

The lower graphs, recording the individual non-nitrogenous anions, show that this is true. It is seen that the great increase of $\mathrm{Cl}$ in the chloride series is associated with anion antagonism, which again is reflected in a marked decline of $S$, whereas $P$ in the herbage remains at practically the same level. The results obtained in the sulphate series fail to show any distinct antagonism which is due to the small recovery of sulphate from the dressing as indicated by the moderate gradient of $\mathrm{S}$.

The problem still remains as to whether the greater sensitivity of $S$ to the increase in $\mathrm{Cl}$ at chloride dressing is related to the fact that sulphate is taken up in the herbage less readily than phosphate. Moreover it still has to be demonstrated that chloride is more readily absorbed than sulphate, since the weaker effect of equivalent sulphate dressings may also originate from a greater interference of the soil system e.g. as a result of limited solubility rendering the applications less effective.

For the study of this relative rate of uptake series of nutrient solutions have been applied in which one of the ions to be compared was gradually replaced by the other ion, the composition otherwise remaining unchanged.

The solutions applied for comparing the rate of uptake of chloride and phosphate have been recorded in table 2. The first treatment includes $1.66 \mathrm{mg}$ equivalents $\mathrm{Cl}$ per liter and no phosphate, the last treatment $1.66 \mathrm{mg}$ equi196 


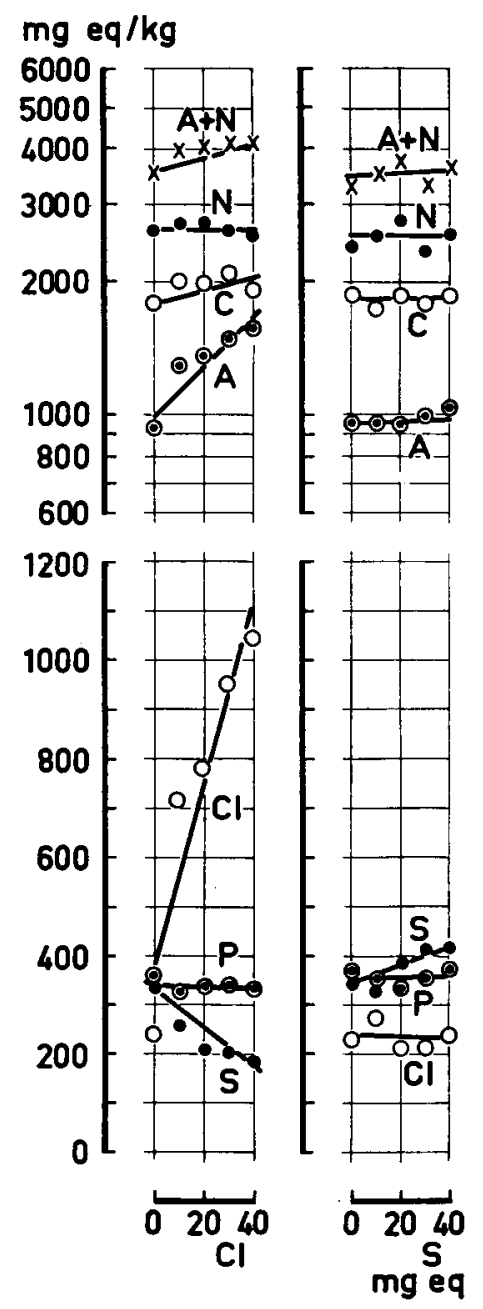

Fig. 1 Effect of InCREasing the NUMBER OF Mg equivalents (Cl) and SULPhate (S) APPLIED TO THE SOIL ON THE MINERAL COMPOSITION IN MG EQUTVALENTS PER KG DRY herbage. P trivalent, N Monovalent.

Table 2 Ionic concentrations of the solutions, in $\mathrm{mg}$ equivalents per liter, applied in the evaluation of the relative rate of uptake of chloride and phosphate.

\begin{tabular}{|c|c|c|c|c|c|c|c|}
\hline \multirow{2}{*}{ solution } & \multicolumn{7}{|c|}{ mg equivalents per liter } \\
\hline & $\mathrm{H}_{2} \mathrm{PO}_{4}$ & $\mathrm{Cl}$ & $\mathrm{NO}_{3}$ & $\mathrm{SO}_{4}$ & K & $\mathrm{Mg}$ & $\mathrm{Ca}$ \\
\hline $\begin{array}{l}a \\
b \\
c \\
d \\
e \\
f\end{array}$ & $\begin{array}{l}0.00 \\
0.33 \\
0.66 \\
1.00 \\
1.33 \\
1.66\end{array}$ & $\begin{array}{l}1.66 \\
1.33 \\
1.00 \\
0.66 \\
0.33 \\
0.00\end{array}$ & & & & & \\
\hline$a-f$ & & & 6.66 & 2.00 & 1.66 & 2.00 & 6.66 \\
\hline
\end{tabular}


valents $\mathrm{H}_{2} \mathrm{PO}_{4}$ and no chloride and the remaining treatments varying proportions of the anions with a sum of $1.66 \mathrm{mg}$ equivalents per liter.

Data on the mineral content of the herbage of the plants, submitted to these treatments, have been recorded in table 3 . The $P$ value of treatment a

Table 3 Mineral composition of the herbage produced on the nutrient solutions a-f of table 2, applied for the evaluation of the relative rate of uptake of chloride and phosphate. $\mathrm{P}$ and $\mathrm{N}$ are included as monovalent anions. The last column indicates the cation-anion ratio: $\mathrm{C} /(\mathrm{A}+\mathrm{N})$.

\begin{tabular}{|c|c|c|c|c|c|c|c|c|c|c|}
\hline \multirow{2}{*}{$\begin{array}{l}\text { solution } \\
\text { applied }\end{array}$} & \multirow{2}{*}{$\begin{array}{c}\text { yield } \\
\text { g d.m. } \\
\text { per } \\
\text { vessel }\end{array}$} & \multicolumn{8}{|c|}{ mg equivalents per $\mathrm{kg}$ dry matter } & \multirow{2}{*}{$\mathrm{C} /(\mathrm{A}+\mathrm{N}$} \\
\hline & & $\mathrm{K}$ & $\mathrm{Na}$ & $\mathrm{Mg}$ & $\mathrm{Ca}$ & $\mathrm{Cl}$ & $\mathrm{P}$ & $S$ & $\mathrm{~N}$ & \\
\hline $\mathrm{a}$ & 30.4 & 599 & 35 & 203 & 489 & 397 & 53 & 152 & 1258 & 0.71 \\
\hline $\mathrm{b}$ & 33.0 & 561 & 29 & 178 & 475 & 349 & 69 & 121 & 1075 & 0.77 \\
\hline $\mathrm{c}$ & 35.8 & 618 & 35 & 198 & 446 & 338 & 103 & 125 & 1211 & 0.73 \\
\hline d & 27.9 & 624 & 29 & 198 & 450 & 290 & 149 & 152 & 1325 & 0.68 \\
\hline e & 33.7 & 527 & 32 & 213 & 475 & 211 & 156 & 119 & 1040 & 0.82 \\
\hline $\mathrm{f}$ & 31.5 & 554 & 35 & 198 & 439 & 169 & 170 & 133 & 1062 & 0.80 \\
\hline
\end{tabular}

and the $\mathrm{Cl}$ value of treatment $\mathrm{f}$, of course, originate from translocation of $\mathrm{P}$ and $\mathrm{Cl}$ initially present in the clipped plants into the growing herbage. Superimposed on this zero levels there is a steady increase in $\mathrm{P}$ and in $\mathrm{Cl}$ in the herbage according to the increase of the rate of application of each of these elements. This increase results from the uptake from the solutions.

In Fig. 2 the $\mathrm{Cl}$ and $\mathrm{P}$ values in $\mathrm{mg}$ equivalents per $\mathrm{kg}$ dry matter have
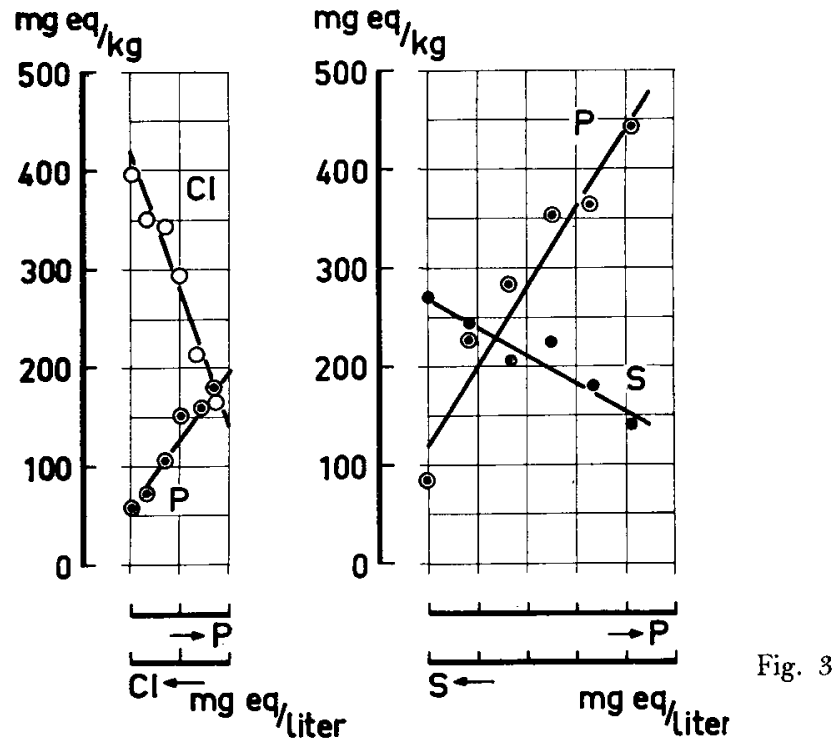

Fig. 2 EfFect of Replacing chloride by phosphate equivalents in the solutions on Cl and $P$ in the herbage. $P$ is Calculated as monovalent.

Abscis: each subdivision represents $1 \mathrm{mg}$ eq per liter, the concentration increases according to the arrows.

Fig. 3 EFFEct of Replacing sulphate by phosphate equivalents in the solutions on $S$ and $P$ in the herbage. P calculated as monovalent.

Abscis : compare legend of figure 2. 
been plotted against the number of $\mathrm{mg}$ equivalents per liter of the solution applied. It appears that the $\mathrm{Cl}$ gradient is steeper than the $\mathrm{P}$ gradient. According to the coefficients of regression, the result of substituting $1 \mathrm{mg}$ equivalent chloride by $1 \mathrm{mg}$ equivalent phosphate per liter is an increase of $\mathrm{P}$ in the herbage of $65( \pm 22)$. Vice verse, the equivalent replacement of phosphate by chloride causes $\mathrm{Cl}$ in the herbage to increase by $142( \pm 10)$.

Since the dry matter yield does not systematically depend on the composition of the solutions, the change in the $\mathrm{P}$ and $\mathrm{Cl}$ concentrations in the herbage is proportional to the change in the total amount of these elements taken up by the herbage. Therefore, it can be inferred from the gradients recorded that the rate of uptake of chloride is about twice as large as that of phosphate. This ratio is only valid, however, for the conditions of the experiment. As a result of uptake the solutions become gradually depleted to an extent depending on the total amount of uptake. Had the yield been greater, e.g. owing to a longer period of regrowth or to denser planting, this amount would have been greater and accordingly depletion would have been more effective in lowering the gradients. Therefore, the absolute values of the gradients have no further meaning, since they relate to the particular condi. tions of the experiment concerning uptake and available amount.

For this reason the results only permit us to draw the general conclusion that chloride is absorbed by the herbage at a relatively greater rate than phos phate. This conclusion does not depend on the actual degree of depletion since more has been absorbed of the ion having the steepest gradient and, accordingly, this ion has been relatively more subject to depletion.

Nitrate was included as the source of nitrogen. Owing to nitrate uptake and utilisation the $\mathrm{pH}$ of the solutions increased from an initial value of 5.2 up to 7.2 during the first two weeks. Thereafter a decline was observed untill a $\mathrm{pH}$ of 6.6 was observed at the end of the regrowth period. The first gradual rise denotes the period of active nitrate uptake and metabolism, while the subsequent fall during the last two weeks indicates that there was not enough nitrate available for further uptake. This depletion is also indicated by the rather low nitrogen content recorded in table 3 . The last column includes the cation-anion ratio $\mathrm{C} /(\mathrm{A}+\mathrm{N})$. According to the low nitrogen level the cation-anion ratio is rather high. The fluctuations reflect an inverse relationship between nitrogen and cation-anion ratio. As a rough approximation $1000 \mathrm{mg}$ equivalents $\mathrm{N}$ corresponds with a value for the ratio of 0.8 . This is close to the value arrived at if the results on nitrogen and cation-anion ratio in nitrogen depleted herbage of increasing age reported earlier (DijksHOORN, 1958 b, Fig. 3 a) are submitted to extrapolation on the same nitrogen level.

The gradual increase of the $\mathrm{pH}$ of the solutions may have converted the phosphate added partly into the divalent state. Although the ionic state of phosphorus during internal translocation to the growing herbage depends on the internal conditions, it is not impossible that the $\mathrm{pH}$ has affected the rate of phosphate uptake via the ionic state in the solution, viz. monovalent or divalent.

For this reason the uptake of phosphate and sulphate has been studied under conditions resulting in a decrease of $\mathrm{pH}$. To this end the clipped plants were kept for the first nine days on tap water and nitrogen was supplied by the addition of $20 \mathrm{ml} 0.5 \mathrm{M}$ ammonium nitrate. After this period of rapid 
regrowth they were transferred to a series of experimental solutions, consisting of mixtures of potassium monophosphate and potassium sulphate without further additions. The initial $\mathrm{pH}$ of these solutions was 4.0 and declined to 3.5 during the subsequent experimental period of two weeks.

Thus, by the application of nitrogen in a seperate stage of the procedure the uptake of phosphate and sulphate could be studied at lower $\mathrm{pH}$ in the absence of the gradual shift to higher values inherent to nitrate utilisation. Due to the reserve of nutrients in the clipped plants regrowth proceeded undisturbed.

The results are summarised in table 4. The first column shows the concentrations in $\mathrm{mg}$ equivalents potassium phosphate and potassium sulphate

Table 4 Yield in g dry matter per vessel and the anionic elements in the herbage of plants kept on the phosphate-sulphate solutions applied in the experiment on the relative rate of uptake of phosphate and sulphate. Phosphorus and nitrogen monovalent. The first column refers to the composition of the solutions.

\begin{tabular}{|c|c|c|c|c|c|c|}
\hline \multicolumn{2}{|c|}{$\begin{array}{c}\text { solutions } \\
\text { mg eq/liter }\end{array}$} & \multirow{2}{*}{$\begin{array}{l}\text { herbage } \\
\text { yield } \\
\text { g d.m. }\end{array}$} & \multicolumn{4}{|c|}{$\begin{array}{c}\text { herbage } \\
\text { mg equivalents per } \mathrm{kg} \text { d.m. }\end{array}$} \\
\hline $\mathrm{KH}_{2} \mathrm{PO}_{4}$ & $\mathrm{~K}_{2} \overline{S O}_{4}$ & & $\mathrm{Cl}$ & $\mathrm{P}$ & $S$ & $\mathrm{~N}$ \\
\hline $\begin{array}{l}0.00 \\
0.83 \\
1.66 \\
2.50 \\
3.32 \\
4.17\end{array}$ & $\begin{array}{l}4.17 \\
3.32 \\
2.50 \\
1.66 \\
0.83 \\
0.00\end{array}$ & $\begin{array}{l}19.6 \\
19.2 \\
19.3 \\
16.6 \\
18.4 \\
17.5\end{array}$ & $\begin{array}{l}403 \\
406 \\
361 \\
431 \\
411 \\
454\end{array}$ & $\begin{array}{r}87 \\
226 \\
281 \\
354 \\
362 \\
444\end{array}$ & $\begin{array}{l}269 \\
244 \\
204 \\
225 \\
179 \\
140\end{array}$ & $\begin{array}{l}1610 \\
1840 \\
1635 \\
2025 \\
1885 \\
1910\end{array}$ \\
\hline
\end{tabular}

per liter of the solutions applied. The values for $\mathrm{P}$ and $\mathrm{S}$, representing the only constituents varied in the treatments, have been plotted against the number of $\mathrm{mg}$ equivalents applied per liter in Fig. 3.

According to the coefficients of regression, the replacement of $1 \mathrm{mg}$ equivalent sulphate by $1 \mathrm{mg}$ equivalent phosphate per liter solution has been associated with an increase of $P$ in the herbage by $78( \pm 10) \mathrm{mg}$ equivalent per $\mathrm{kg}$ dry weight. Vice versa, the substitution of $1 \mathrm{mg}$ equivalent phosphate by $1 \mathrm{mg}$ equivalent sulphate has resulted in an increase of $\mathrm{S}$ by $29( \pm 5) \mathrm{mg}$ equivalents per $\mathrm{kg}$ dry herbage.

This result shows that phosphate has been taken up by the herbage about twice as readily as sulphate. In this instance also the composition had no marked effect on the yield. The fluctuations in the yield (table 4) may have their origin in errors in the density of planting and they do not exceed 10 per cent of the mean. It is therefore safe to use the gradients directly for assessing the relative rate of uptake.

Within the experimental error the $P$ gradient is the same as that found in the experiment on chloride-phosphate substitution. Therefore, no indication is obtained that phosphate is more readily absorbed from more acidic solutions. The somewhat higher $\mathrm{P}$ gradient in the second experiment may have resulted from the lower yield level and a correspondingly less advanced depletion of the solutions.

Since the anions have been compared in twos and the conclusions have been restricted to the qualification which of the two anions is more readily absorbed in the herbage, it is reasonable to derive from both experiments 
a general conclusion, stating that the relative rate of uptake of the anions is denoted by the order:

$$
\text { chloride }>\text { phosphate }>\text { sulphate. }
$$

This order of rate of uptake agrees with the forecast based on the observations on anion antagonism.

The uptake of elements by the herbage implies transport through the roots and basal parts to the tops. It is possible that the rate of this uptake is connected with a resistance to translocation, for example by adsorption to the plant material which the ions have to traverse. It is conceivable, for instance, that the rate of uptake will be greater according as there is less chance of adsorption which hinders mobility. In such a case we may expect an analogy between the order according to the rate of uptake and the distribution of the various elements over different parts of the herbage, as the latter be connected with a redistribution from older to younger parts of the plant.

This analogy may appear from data recorded by KEMP and Dijksнoons (1956) on the mineral content of the top and bottom parts of grass herbage. Redistribution coefficients can be deduced from their percentage data (samples 3-7) by dividing the values in the bottom parts by those in the top parts. The redistribution coefficients thus obtained have been listed in table 5. They

Table 5 Redistribution coefficients of chlorine, phosphorus and sulphur, calculated from the data of KEMP and DiJkshoon (1956) on the percentage found in the lower and upper parts of grass herbage.

\begin{tabular}{c|c|c|c}
\hline sample & $\mathrm{Cl}$ & $\mathrm{P}$ & $\mathrm{S}$ \\
\hline 3 & 1.42 & 1.07 & 0.81 \\
4 & 1.54 & 0.97 & 1.02 \\
5 & 1.57 & 1.01 & 0.82 \\
6 & 1.19 & 1.06 & 0.74 \\
7 & 1.24 & 1.10 & 0.61 \\
\hline mean & 1.39 & 1.04 & 0.80 \\
\hline
\end{tabular}

reflect the relative tendency of the elements to migrate from the older leaves to the lowest younger parts in the growth zones.

It appears from the values of the redistribution coefficient that the redistribution tendency is also reflected in the order:

$$
\text { chloride }>\text { phosphate }>\text { sulphate. }
$$

Since the same order follows from the study of anion antagonism, the relative rate of uptake from solutions and the process of redistribution, it would appear to represent a general aspect of the mobility of these elements with respect to uptake in the herbage and redistribution.

\section{REFERENCES}

Dijkshoors, W. : Neth. Journ. of Agric. Sci. 5 (1957) 233.

- - : Neth. Journ. of Agric. Sci. 6 (1958 a) 131.

- - : Neth. Journ. of Agric. Sci. 6 (1958 b) 211.

KeMP, A. and W. DiJkshoorn: Verslag C.I.L.O. over 1955 (1956) 100. 